\title{
DOES COMPETITIVELY DISTINCT OPERATION ENABLE PERFORMANCE IN TURBULENT BUSINESS ENVIRONMENT? A STUDY ON FINNISH SMES
}

\author{
Binod Timilsina \\ Department of Production, University of Vaasa, Finland \\ Corresponding author: \\ Binod Timilsina \\ Department of Production \\ University of Vaasa \\ Wolffintie 34, 65200 Vaasa, Finland \\ phone: $(+358) 466237496$ \\ e-mail: binod.timilsina@uwasa.fi
}

Received: 1 June 2016 Accepted: 15 July 2016

\begin{abstract}
Aligning resource choice and operations decision in the value chain (input-process-output) is one of the most important functions of a firm not only to make its operations to be competitively distinct but also very important for the firm's growth and survival. However, the role of competitively distinct operations in maintaining better performance in dynamic and changing business environment has remained unclear. Therefore, this paper examined the relationship between competitively distinct operations, high efficiency operations and operational performance (research model one). In the similar manner the relationship between turbulent business environments, operational performance and financial performance were also examined (research model two). The study was conducted considering survey responses from 61 small and medium size enterprises from Finland. Correlation test and structural path modelling was used to test and validate the proposed hypothesis and research model. The results showed that competitively distinct operation enables high efficiency operations, which influences operational performance positively and significantly. In the similar manner, operational performance influences financial performance positively and significantly. Likewise, turbulent business environment was found to have a negative impact on operational and financial performance. The research findings are found to be adequate enough to highlight the importance of aligning resource choice and operations decisions in reducing the impact of turbulent business environment on organizational performance.
\end{abstract}

KEYWORDS

competitively distinct operations, high efficiency operations, turbulent business environment, operational performance, financial performance.

\section{Introduction}

The significant technological advancements, globalization of companies, increased product and service innovation, and rapidly changing consumer needs not only provides the opportunities, but also are the source of turbulence in a business environment. Either to compete in the market place or to meet the needs of the rapidly changing business environment, companies are facing more challenges than ever before, especially small and medium size enterprises. Firm's strategies are influenced by managerial perception of business environment which has significant impact on firm performance [1]. Therefore, in rapidly changing business environment, firms are forced to continuously integrate resource choice and operations decisions not only to survive and compete but also to maintain the desired level of performance. According to [2] alignment between strategies and capabilities is necessary to compete successfully. Referring to resource based view of the firm [3] says sustainability of competitive advantage in a rapidly changing business environment depends on the firm's capability to reconfigure and redeploy resources. This indicates that better the fit between changing business environment, resource choice, and operations 
decision better the firm performance. Therefore, this paper argues that environmental turbulence and firm's capabilities are the key determinants of firm performance. Here, environmental turbulence is defined as the conditions when available information, knowledge and experiences are not sufficient or do not allow decision making or predicting the future outcome of an event, as for example investment decisions [4]. Likewise, firm's capability is defined as the firm's ability to align resource choice and operations decision in the value chain (input-process-output).

Given the ever changing nature of business environment there is continuous demand of dynamic decision support system that could integrate resource choice and operations decision simultaneously. In this context, basing on theoretical considerations supported by an example from Walmart [5] has proposed a "Decision framework for efficient resource choice and operations decision: Design of competitively distinct operations" and argued that competitively distinct operations (CDO) have positive impacts on firm performance. Here, CDO means the operations decision based on optimal balance between resource choices and operations decisions gained through cost-benefit analysis [5]. The proposed study goes one step further from theoretical considerations to empirical testing and assesses the relationship between CDO, high efficiency operations, and operational performance. Furthermore, the study also seeks to assess the impact of environmental turbulence on operational and financial performance. The result and finding contribute to the existing discussion on the ways of mitigating the impact of changing business environment on organizational performance, thus bridging the gap between theory and practice, and finally aims to open doors for future research.

\section{Literature review}

\section{Competitively distinct operations}

Operational decisions are the strategic approach that helps to determine the best possible way in utilizing the available resources. Likewise, resource allocation is a move towards optimization of opposing objectives that share common resources [6] and plays an important role in the performance outcome of an organization [7]. Through the example of process industries [8] says optimal resource allocation and lean operations helps to reduce the production cost. In business practices, resource choice and operation decisions are mutually inclusive events where operations and operational routine drives the resources towards organizational goal. Therefore, in order to have better and consistent performance and to maximize the utility of available resources, there must be a logical and coherent relationship between resource choice and operations decision, especially during the turbulent business environment. In the similar manner, operations can be defined as the act of gaining higher customer satisfaction and net profit while reducing waste, cycle time, capital investment and operating cost [9]. In fact operations add value and convert inputs, i.e. resources into desired output, i.e. goods or services [10], hence, the effectiveness of a firm lies in the operationalization of resources i.e. how resources are perceived and deployed. According to [11] economic performance of a firm is affected by operational routine, resources and competencies. Likewise, operations alone hold 60-80 percent of direct expenses, an obstruction to the firm's performance [12]. In other words, operations guarantee better performance through available resources. Therefore, a strong control over cost related to operations is one of the accepted traits of successful business [13]. This means the process of resource coordination, configuration, utilization and deployment needs to be unique, cost efficient, and result-oriented. Through a proper alignment between resource choice and operation decision an organization can optimize its resources, increase system reliability and finally experience a better performance. According to [14:521] it is important for firms "to scan the environment, to evaluate markets and competitors, and quickly accomplish reconfiguration and transformation ahead of competition". This view is supported by [5] and says a proper alignment between resource choice and operations decision not only allows a firm to reconfigure the present concentration of resources and increase the performance of the weak operations, but also helps an organization to narrow down and find the areas to focus for better performance. For an efficient resource choice and operations decisions [5] has proposed the concept of competitively distinct operations (CDO) that helps not only to identify the best possible combination of resource choice and operations decisions, but also allows for constant alignment between resource choice and operations decision, and finally makes firm's operations to be competitively distinct. Here, CDO is the result of a series of actions, in short, first identify the needs, examine the resource availability and define the firm's objectives, second, set the target goal, third, make a cost benefit analysis to select the right combination of resource choice and operations decisions, fourth, choose the best alternative, fifth implement the plan, and finally benchmark the results with targeted goals if necessary repeat the process. 
Thus, CDO enables a firm with better abilities not only in predicting an event, but also to change itself from one mode of actions to another by aligning resources and operations decisions in the value chain (input-process-output). More specifically, competitively distinct operation shows the underlying difference between competing firms in terms of productivity, efficiency and profitability through high efficiency operations. However, organization projecting and anticipating environmental changes correctly should have higher performance [15].

\section{High efficiency operations}

Turbulent business environment is the result of market conditions, competitors' position and regulatory body [16]. In practice turbulence in the business environment is an extent or measure of resource transfer between different stakeholders. In order to make a balance in the mechanism of resource transfer business entities should make adjustments in resource choice and operation decisions. Also, to adopt the change and maintain the desired level of performance the rate of resource exchange needs to be balanced with the rate of change in internal and external environment. As the level of turbulent business environment increases, the firm must reconfigure its resource choice and operation decision to maintain the desired level of performance. The success of a firm during turbulent time depends on the effectiveness of allocation of available resources and its use in value creation. Therefore, in turbulent times CDO (see previous section) can be an effective approach not only in reconfiguring resource choice and operation decision but also in restoring firm's growth through high efficiency operations. Here, high efficiency operations are defined as the operational situation with clarity and reduced uncertainty gained through synchronization of dependent activities and direct communication of needs, which allows high controllability through efficient allocation of resources and low commitment [17]. According to [18] conceptualization of strategy, sharing of strategic responsibility within the firm and putting focus on organizational capabilities helps in dealing with environmental turbulence. Similarly, competence and resources plays a functional role in organizational success [19]. This is consistent with [20] who concluded that managerial planning and skills facilitate business success. Therefore, the managers of the performance oriented firm should be able to optimize resources \& cost, should have a better operational situation, direct communication of needs so that better control can be achieved through resource choice and operations decision. Accordingly, it is reasonable to say that there must be a good fit between resource choice and operations decisions to gain high efficiency operations, which finally enhance operational performance. On the other hand a poor fit might lead to low efficiency operations and finally low operational performance. Here, the low efficiency operations are defined as the operational situation with higher uncertainty gained through decoupling of dependent activities and accumulation of needs which results in low controllability because of inefficient allocation of resources and high commitment [17]. Given the same set of business environment, the organization with better resource choice [21], and operations decision will experiences less environmental uncertainty in comparison with organizations with poor resource choice and operations decision.

\section{Turbulent business environment}

Every organization carries out its activities in response to the changing business environment, i.e. the organization relay and serve the surrounding environment; this means the organizations are environmental dependent $[22,23]$. Broadly, the organizational environment can be divided in two groups: first, external environment (social, political, technological and economic), and the second, internal environment (resources and capabilities), which has significant impact on the life and the development of an organization $[24,25]$. In the literature turbulence in the business environment has been defined as an environment having a high level of interconnection between an organization and changes in the surrounding [26]. Similarly, [27] define environmental turbulence as a group measure of changeability and predictability of the operating environment of a firm. A similar view is proposed by [28] and defines environmental turbulence as the rate of unpredictability of changes occurring in the external business environment. Environmental turbulence is the result of complexity, dynamism and uncertainty [29]. However, turbulence in business environment refers to the conditions when available information, knowledge and experience is not sufficient or do not allow decision making or predicting the future outcome of the firm's operation. As a result the environment becomes more complex, organization may not be able to predict the results of their own actions [30]; organizational behavior and performance is constrained [31], also, there is a possibility that organization may lose stability in the market [32]. In the previous studies it has been found that turbulence in the business environment has negative impact on firm performance. For example: [33] found a negative relationship between environmental dynamism and firm performance. In the similar manner, [34] also found that Environmental turbulence 
(munificence, hostility, dynamism and complexity) affects entrepreneurial orientation, which finally affects firm performance. According to [35] the capability gap experienced by a firm is higher in a turbulent business environment. Hence, a firm experiences low levels of performance during dynamic environment in comparison to a stable environment.

\section{Research model and hypothesis}

Based on the literature review following two research model are proposed for the present study. The first research model is concerned with competitively distinct operations, high efficiency operations, and operational performance while the second model is concerned with turbulent business environment, operational performance and financial performance.

The research model one (Fig. 1) illustrates that competitively distinct operations influences high efficiency operations, which finally influences firm's operational performance. It is suggested that CDO leads to HEO which then leads to operational performance. Therefore, to investigate the relationship between CDO, HEO and OP following two hypotheses are proposed.

Hypothesis one (H1): Competitively distinct operation has a positive and significant impact on high efficiency operations.

Hypothesis two (H2): High efficiency operation has a positive and significant impact on operational performance.

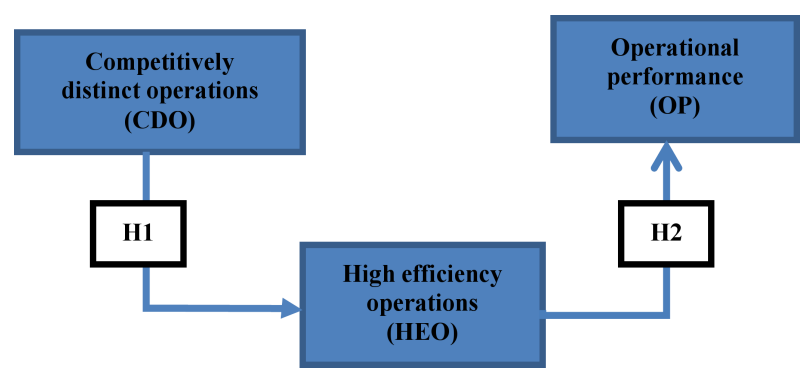

Fig. 1. Research model one.

The research model two (Fig. 2) illustrates that turbulent business environment influences firm's operational performance, which finally influences firm's financial performance. It is suggested that TE impacts firm's OP and OP impacts FP. In addition, it is also suggested that ET impacts firm's FP. Therefore, to investigate the relationship between ET, OP and FP following three hypotheses are proposed.

Hypothesis three (H3): Turbulent business environment has a negative and significant impact on firm's operational performance.
Hypothesis four (H4): Operational performance has a positive and significant impact on firm's financial performance.

Hypothesis five (H5): Turbulent business environment has a negative and significant impact on firm's financial performance.

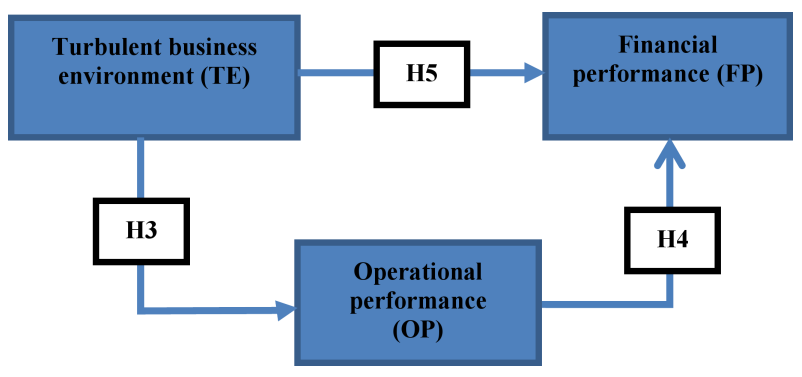

Fig. 2. Research model two.

\section{Research methodology}

\section{Study population, sample and data collection}

The data required for this study were collected from Finnish SMEs through an online survey. The sample was acquired from Orbis data base accessed through University of Vaasa's web portal. According to the requirement of the proposed study different criteria were used to select the companies. As for example company size, Finland, director/manager contact information. Emails starting with info, office, toimisto, opisto, and few more were deleted from the short listed emails. This was done to get the information directly from company director/manager and reduce the sample size. Likewise, personal emails (e.g. Gmail, Hotmail, Yahoo) were also removed from the list. Finally, random sampling method was used to select the 500 emails for the final survey. There were 61 (response rate $12.2 \%$ ) respondents who participated in the online survey, representing 10 micro enterprises (1-9 employees), 33 small enterprises (1049 employees), 17 medium size enterprises (50-249 employees) and one large enterprise (above $250 \mathrm{em}-$ ployees). Among these 61 respondents there were 9 managers, 23 directors, 28 owners and one person working in other positions in the company. In the similar manner, there were 5 primary (industry making use of natural resources and includes the agriculture, forestry and fishing, mining, and extraction of oil and gas sector), 13 secondary (industries using raw materials supplied by the primary sector), and 43 tertiary (industries involved in the service sector) sector of industries. 


\section{Data analysis}

The collected data from the survey were analyzed through SmartPLS 2.0, a variance based structural equation (SEM) modeling using the partial least squares (PLS) method. The SmartPLS 2.0 was used because of a few reasons: (i) with small sample size PLS model exhibits more stable results [36], (ii) PLS modelling is especially suitable when the measures are new and have not been tested previously [37], (iii) PLS modelling offers less sensitivity to a smaller sample size and can be used for testing theory and the relationship between variables [38], and (iv) [39] suggested that PLS path modelling can be used to confirm the relevance of indicators with sample size as low as twenty; similarly [40] has illustrated low sample size requirement in path modelling by analyzing a data set of ten observations. Thus, basing on the sample size (61) considered in this research and suggestion from the previous studies, SmartPLS 2.0 found appropriate for data analysis. The data were analyzed in different stages, for instance: construct reliability and validity (convergent and discriminant), Pearson correlation, and finally, the acceptance or rejection of the proposed hypothesis was made through T-value.

\section{Measurement and scale}

Environmental turbulence, competitively distinct operations, high efficiency operations, operational performance and financial performance were the different latent variables used in this research. Likert scale ranging from 1 to 5 was used measure the respondent view for each item employed in the survey. The different measures considered in this research were as mentioned below.

\section{Measures of turbulent business environment (ET)}

In the literature, environmental turbulence has been measured in different ways, as for example: [41] measure environmental turbulence in terms of market turbulence, competitive intensity, and technological turbulence while [42] measures environmental turbulence in terms of dynamism, munificence, and complexity. However, turbulent business environment is the conditions when a firm is not able to predict and adopt the changes occurring in the business environment; it might be due to dynamism, complexity, technological change or competitive intensity. Therefore, the construct to measure turbulent business environment was mainly related to the capability to understand, predict and adopt the changes occurring in terms of competitor's move and customer's requirement. Also, the construct were reverse coded, the reason for reverse coding can be explained with an example. Let's consider the first construct "It is very easy to understand the competitors move" one respondent strongly agrees, while the other respondent strongly disagrees with the statement. Basing on the posed definition of environmental turbulence first respondent is exposed to low level of environmental turbulence while second respondent is exposed to high level of environmental turbulence, so is with the other construct considered in the research. From the definition of environmental and the given example it is clear that " $1=$ strongly disagree" corresponds to high and " $5=$ strongly agree" corresponds to low level of environmental turbulence, therefore, all the construct of environmental turbulence was reverse coded.

In order to measure the turbulence in business environment, respondents were asked to answer the question: In the context of your organization, do you agree with the following statement? (1 = strongly disagree to $5=$ strongly agree).

ET1. It is very easy to understand the competitors move (R) [33].

ET2. It is very easy to understand the customer and market requirement $(\mathrm{R})$ [33].

ET3. We have always been able to predict the changes occurring in our market $(\mathrm{R})$.

ET4. It has always been easy to adopt the changes occurring in the market $(\mathrm{R})$.

\section{Measures of competitively distinct operation (CDO)}

Competitively distinct operation is the action plan based on optimal balance between resource choice and operation decision gained through costbenefit analysis [5]. To make the operations to be competitively distinct a series of action needs to be followed, which are considered as the measures of competitively distinct operations, but these measures have not been considered for statistical analysis in previous studies. In order to measure the level of competitively distinct operation, respondents were asked to answer the question: In the context of your organization, what is the level of emphasis given to the following actions in making resource choice and operations decisions? ( $1=$ no emphasis to $5=$ strongly emphasized).

CDO1. Identification of internal and external needs. CDO2. Examination of the available resources.

CDO3. Defining the firm's objectives.

CDO4. Setting the target/goal to accomplish.

CDO5. Consideration of cost of operations.

CDO6. Consideration of opportunity cost. 
CDO7. Consideration of cost of resources.

CDO8. Consideration of possible output that could be generated.

\section{Measures of high efficiency operations (HEO)}

The measures of high efficiency operations considered in this research were adopted from [17], but these measures have not been considered for statistical analysis in previous studies. According to the author high efficiency operation is the operational situation with low uncertainty gained through synchronization of dependent activities, direct communication of needs, and efficient allocation of resources. Therefore, in order to measure the level of high efficiency operation, respondents were asked to answer the question: In the context to your organization, do you agree with the following statement? $(1=$ strongly disagree to $5=$ strongly agree).

HEO1. We have synchronization of dependent activities.

HEO2. We have direct communication of needs.

HEO3. We have clarity in our operations and activities.

HEO4. We have an efficient allocation of resources.

\section{Measures of operational performance (OP)}

Operational performance reflects the better operationalization of firm resources; in practices it is quite difficult to measure the operational performance with a single measure. Therefore, the level of operating cost, competitive position, market share, and level of customer satisfaction has been assessed to measure the level of operational performance. In the survey, respondents were asked to answer the question: In the context of your organization, do you agree with the following statement? $(1=$ strongly disagree to $5=$ strongly agree).

OP1. We have a reduction in operating cost.

OP2. We have effective value chain activities at a lower cost.

OP3. We have better competitive position in the market.

OP4. We have improvement in productivity.

OP5. We have increased in market share.

OP6. We have improvement in customer satisfaction.

\section{Measures of financial performance (FP)}

In the literature objectives measures of performance has been widely accepted to measure the financial performance of a firm. Considering the common practice of objective measures of financial performance following measures were adopted to measure financial performance.
FP1. Return on investment.

FP2. Return on assets.

FP3. Net profit.

\section{Construct reliability}

Widely accepted measure Cronbach's alpha was calculated to measure the internal consistency, here, internal consistency means the degree of interrelatedness of the construct. As a rule of thumb [43] proposes an acceptable value of Cronbach's alpha to be 0.70. The Table 1 below summarizes the calculated values of Cronbach's alpha, which shows that the value of Cronbach's alpha ranged from 0.70 to 0.92 providing the evidence for construct reliability.

Table 1

Results of Cronbach's alpha.

\begin{tabular}{l|c}
\hline \multicolumn{1}{c|}{ Latent variables } & $\begin{array}{c}\text { Cronbach's } \\
\text { alpha }\end{array}$ \\
\hline Competitively distinct operations (CDO) & 0.81 \\
\hline High efficiency operations (HEO) & 0.72 \\
\hline Operational performance (OP) & 0.75 \\
\hline Environmental turbulence (ET) & 0.70 \\
\hline Firm performance (FP) & 0.92 \\
\hline
\end{tabular}

\section{Convergent and discriminant validity}

According to [44] following three criteria needs to be maintained to establish the construct validity: First, the average variance (AVE) for each construct should be $>0.50$; this is the desired level of AVE which means the $50 \%$ of variance is captured by a construct in relation to the variance amount due to measurement error. However, in the literature AVE value of 0.42 and 0.43 has been accepted to establish convergent validity by [45:1247] and [46:430] respectively. This means AVE with value 0.42 can be accepted to establish the convergent validity. The calculated values of AVE are shown in the Table 2, which shows that all the values of AVE were found to be $\geq 0.42$. Hence, the measurement items of latent variables can be considered as valid construct.

Table 2

Results of composite reliability (CR) and average variance extracted (AVE).

\begin{tabular}{l|l|l}
\hline & CR & AVE \\
\hline \multicolumn{2}{l}{ Model one } \\
\hline CDO & 0.85 & 0.42 \\
\hline HEO & 0.82 & 0.54 \\
\hline OP & 0.82 & 0.44 \\
\hline Model two \\
\hline ET & 0.80 & 0.50 \\
\hline FP & 0.95 & 0.86 \\
\hline OP & 0.82 & 0.44 \\
\hline
\end{tabular}


Second, the value of composite reliability (CR) for each construct should be $>0.7$; the calculated values of CR ranged from 0.803 to 0.946 (see Table 2) suggesting that the indicators were reliable and valid measures of latent variables.

Third, all item factor loading should be significant and >0.70, however, [47:60] suggests 0.30 as the cutoff value for factor loading while [48:96] suggests 0.40 as the cutoff value for factor loading. In the similar manner [49] suggests all item factor loading should be $>0.50$ and significant. The calculated values of factor loading are shown in the Table 3 (research model one) and Table 4 (research model two), which shows that all the values of factor loading were significant and found to be greater than 0.50 (see Table 3 and 4). Also the factor loading for all construct was found to be higher than their cross loading suggesting that the item were a good indicator of the proposed latent variables.

Thus, based on the evidence from the existing literature and the calculated values of $\mathrm{CR}, \mathrm{AVE}$ and factor loading (see Tables 2, 3 and 4), the convergent validity was established.

Furthermore, [44] suggested that to establish discriminant validity the square root of AVE of a construct should be $>$ its correlation with other constructs. The calculated values of square root of AVE was found to be greater than its correlation with other construct (see Table 5 and 6 ), the numbers on the diagonal are the values of the square root of AVE. Thus the discriminant validity was established.

Table 3

Results of factor loading and cross loading (Model one).

\begin{tabular}{|c|c|c|c|c|c|}
\hline Variables & $\mathrm{EDO}$ & $\mathrm{HEO}$ & $\overline{\mathrm{OP}}$ & T-values & P-values \\
\hline $\mathrm{CDO} 1 \leftarrow \mathrm{CDO}$ & 0.56 & 0.46 & 0.36 & 3.71 & 0.000 \\
\hline $\mathrm{CDO} 2 \leftarrow \mathrm{CDO}$ & 0.58 & 0.23 & 0.05 & 3.20 & 0.001 \\
\hline $\mathrm{CDO} 3 \leftarrow \mathrm{CDO}$ & 0.74 & 0.48 & 0.38 & 5.59 & 0.000 \\
\hline $\mathrm{CDO} 4 \leftarrow \mathrm{CDO}$ & 0.68 & 0.41 & 0.22 & 5.06 & 0.000 \\
\hline $\mathrm{CDO} 5 \leftarrow \mathrm{CDO}$ & 0.69 & 0.32 & 0.07 & 3.92 & 0.000 \\
\hline $\mathrm{CDO} 6 \leftarrow \mathrm{CDO}$ & 0.67 & 0.41 & -0.01 & 4.51 & 0.000 \\
\hline $\mathrm{CDO} 7 \leftarrow \mathrm{CDO}$ & 0.72 & 0.26 & -0.02 & 4.23 & 0.000 \\
\hline $\mathrm{CDO} 8 \leftarrow \mathrm{CDO}$ & 0.54 & 0.37 & 0.21 & 2.61 & 0.009 \\
\hline$\overline{\mathrm{HEO} 1 \leftarrow \mathrm{HEO}}$ & 0.53 & 0.72 & 0.45 & $\overline{6.42}$ & 0.000 \\
\hline $\mathrm{HEO} 2 \leftarrow \mathrm{HEO}$ & 0.48 & 0.77 & 0.28 & 7.20 & 0.000 \\
\hline HEO3 $\leftarrow$ HEO & 0.40 & 0.76 & 0.42 & 7.08 & 0.000 \\
\hline $\mathrm{HEO} 4 \leftarrow \mathrm{HEO}$ & 0.29 & 0.67 & 0.25 & 6.75 & 0.000 \\
\hline 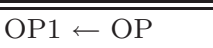 & 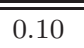 & 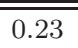 & 0.70 & $\overline{5.19}$ & 0.000 \\
\hline $\mathrm{OP} 2 \leftarrow \mathrm{OP}$ & 0.17 & 0.31 & 0.64 & 4.89 & 0.000 \\
\hline $\mathrm{OP} 3 \leftarrow \mathrm{OP}$ & 0.15 & 0.23 & 0.60 & 3.24 & 0.001 \\
\hline $\mathrm{OP} 4 \leftarrow \mathrm{OP}$ & 0.26 & 0.35 & 0.74 & 5.27 & 0.000 \\
\hline $\mathrm{OP} 4 \leftarrow \mathrm{OP}$ & 0.18 & 0.22 & 0.57 & 2.64 & 0.009 \\
\hline $\mathrm{OP} 4 \leftarrow \mathrm{OP}$ & 0.22 & 0.48 & 0.71 & 5.47 & 0.000 \\
\hline
\end{tabular}

Table 4

Results of factor loading and cross loading (Model two).

\begin{tabular}{|c|c|c|c|c|c|}
\hline Variables & $\mathrm{ET}$ & FP & OP & T-values & P-values \\
\hline $\mathrm{ET} 1 \leftarrow \mathrm{ET}$ & 0.58 & -0.18 & -0.06 & 3.21 & 0.001 \\
\hline $\mathrm{ET} 2 \leftarrow \mathrm{ET}$ & 0.57 & 0.00 & -0.18 & 3.36 & 0.001 \\
\hline $\mathrm{ET} 3 \leftarrow \mathrm{ET}$ & 0.87 & -0.43 & -0.31 & 14.94 & 0.000 \\
\hline $\mathrm{ET} 4 \leftarrow \mathrm{ET}$ & 0.78 & -0.25 & -0.30 & 7.35 & 0.000 \\
\hline $\mathrm{FP} 1 \leftarrow \mathrm{FP}$ & -0.33 & 0.95 & 0.54 & 60.10 & 0.000 \\
\hline FP2 $\leftarrow$ FP & -0.36 & 0.96 & 0.50 & 75.57 & 0.000 \\
\hline $\mathrm{FP} 3 \leftarrow \mathrm{FP}$ & -0.39 & 0.86 & 0.45 & 18.08 & 0.000 \\
\hline$\overline{\mathrm{OP} 1} \leftarrow \mathrm{OP}$ & -0.14 & 0.16 & 0.63 & 3.42 & 0.001 \\
\hline $\mathrm{OP} 2 \leftarrow \mathrm{OP}$ & -0.22 & 0.32 & 0.61 & 3.31 & 0.001 \\
\hline $\mathrm{OP} 3 \leftarrow \mathrm{OP}$ & -0.20 & 0.33 & 0.68 & 5.88 & 0.000 \\
\hline $\mathrm{OP} 4 \leftarrow \mathrm{OP}$ & -0.08 & 0.46 & 0.72 & 4.41 & 0.000 \\
\hline $\mathrm{OP} 5 \leftarrow \mathrm{OP}$ & -0.34 & 0.47 & 0.72 & 8.42 & 0.000 \\
\hline $\mathrm{OP} 6 \leftarrow \mathrm{OP}$ & -0.31 & 0.24 & 0.61 & 3.72 & 0.000 \\
\hline
\end{tabular}

Table 5

Results of latent variable correlations (Model one).

\begin{tabular}{l|c|c|c}
\hline Latent variables & CDO & HEO & OP \\
\hline CDO & $\mathbf{0 . 6 5}$ & & \\
\hline HEO & 0.60 & $\mathbf{0 . 7 3}$ & \\
\hline OP & 0.28 & 0.49 & $\mathbf{0 . 6 6}$ \\
\hline
\end{tabular}

Table 6

Results of latent variable correlations (Model two).

\begin{tabular}{l|c|c|c}
\hline Latent variables & ET & OP & FP \\
\hline ET & $\mathbf{0 . 7 1}$ & & \\
\hline FP & -0.39 & $\mathbf{0 . 9 3}$ & \\
\hline OP & -0.34 & 0.54 & $\mathbf{0 . 6 6}$ \\
\hline
\end{tabular}

\section{Analytical results}

\section{Significance of the proposed hypothesis}

The results from the SmartPLS 2.0 were examined to test the proposed hypothesis in research model one and two. The obtained results from the PLS structural model are presented in the following Table 7 .

Table 7

Results of structural path in the model.

\begin{tabular}{|c|c|c|c|c|}
\hline Hypothesis & Sign & $\begin{array}{l}\text { PLS path } \\
\text { coefficient } \\
(\beta)\end{array}$ & $\begin{array}{c}\text { T-value } \\
(\mathrm{T})\end{array}$ & $\begin{array}{c}\text { P-value } \\
(\mathrm{P})\end{array}$ \\
\hline \multicolumn{5}{|c|}{ Research model one } \\
\hline $\mathrm{CDO} \rightarrow \mathrm{HEO}$ & + & 0.60 & 7.10 & 0.000 \\
\hline $\mathrm{HEO} \rightarrow \mathrm{OP}$ & + & 0.49 & 4.69 & 0.000 \\
\hline \multicolumn{5}{|c|}{ Research model two } \\
\hline $\mathrm{ET} \rightarrow \mathrm{FP}$ & - & 0.23 & 2.11 & 0.036 \\
\hline $\mathrm{ET} \rightarrow \mathrm{OP}$ & - & 0.34 & 3.27 & 0.001 \\
\hline $\mathrm{OP} \rightarrow \mathrm{FP}$ & + & 0.46 & 4.29 & 0.000 \\
\hline
\end{tabular}

Volume 7 • Number $3 \bullet$ September 2016 
The results from the PLS structural model presented in Table 7 showed a positive and significant relationship between $\mathrm{CDO}$ and HEO with values $\beta=0.60, T=7.10, P=0.000$, supporting the hypothesis one (H1). Also, the relationship between HEO and OP found to be positive and significant with values $\beta=0.49, T=4.69, P=0.000$, supporting the hypothesis two (H2). Furthermore, the relationship between ET and FP was found to be negative and significant with values $\beta=0.23$, $T=2.11, P=0.036$; supporting the hypothesis three (H3). The relationship between ET and OP found to be negative and significant with values $\beta=0.34, T=3.27, P=0.001$, supporting the hypothesis four (H4). Similarly, the relationship between OP and FP found to be positive and significant with values $\beta=0.46, T=4.29, P=0.000$; supporting hypothesis five (H5).

\section{Interpreting the coefficient of determination $\left(\mathbf{R}^{2}\right)$}

In the literature $\mathrm{R}^{2}$ values with $0.67,0.33$ and 0.19 has been described as substantial, moderate and weak respectively [38], this means higher the value of $\mathrm{R}^{2}$ better the model fit. On the other hand [50] and [51] says for a meaningful interpretation $10 \%$ criterion should be achieved. Here, the values of R-square found to be above $10 \%$, in the research model one the values of $\mathrm{R}^{2}$ was found to be 0.354 and 0.244 for HEO and OP respectively. This means $35.4 \%$ variation in HEO can be accounted for CDO and $24.4 \%$ variation in OPER can be accounted for HEO. Similarly, in research model two the values of $\mathrm{R}^{2}$ were found to be 0.33 and 0.12 for $\mathrm{FP}$ and $\mathrm{OP}$ respectively. This means $33 \%$ variation in FP can be accounted for $\mathrm{ET}$ and OP, similarly, a $12 \%$ variation in OP can be accounted for ET. Thus, based on the evidence from the literature and the calculated values of $\beta, T$ and $P$ (see Table 7 ) and $\mathrm{R}^{2}$ it is plausible to say that the model is adequate enough to explain the impact of $\mathrm{CDO}$ on $\mathrm{HEO}$ and the consequent impact of HEO on OP (research model one), and also to explain the impact of ET on OP and FP and the consequent impact of OP on FP (research model two).

\section{Discussion and conclusions}

This study not only advanced the theoretical model of competitively distinct operations proposed by [5] but also argued that the impact of turbulent business environment on firm performance can be reduced with continuous alignment between resource choice and operations decision in the value chain (input-process-output). In the previous study a similar thought is proposed by [52] and says in a changing business environment a firm's success and survival is determined by the firm's capability to acquire, maintain and take advantage from the right combination of capabilities. Therefore, the companies aligning resource choice and operations decisions with the changing business environment will have better competitive positions in the market.

The proposed research model (see Fig. 1 and 2) was tested and validated using correlation test and structural path modelling at different stages. The correlation test results showed a strong relationship between the examined variables (see Tables 5 and 6 ). In the similar manner, the results from structural path in the model showed a positive and significant relationship between competitively distinct operations, high efficiency operations and operational performance (see Table 7). However, the direct relationship between CDO and operational performance was found to be insignificant. This is consistent with the findings of [53] supporting the view of internal contingency and claimed that resources and strategies aligned together leads to better performance. Likewise, the relationship between operational performance and financial performance was also found to be positive and significant (see Table 7). Furthermore, the relationship between environmental turbulence and operational performance found to be negative and significant (see Table 7). Similarly, the relationship between environmental turbulence and financial performance found to be negative and significant (see Table 7); this finding is consistent with [33] and [54], who argued that environmental dynamism has negative influence on firm performance. Therefore, the companies should consider environmental factors in developing, choosing and implementing strategies [55].

On the basis of research findings, it can be concluded that the impact of turbulent business environment can be mitigated through proper alignment between resource choice and operations decision. This is because of three reasons, first, competitively distinct operations enables high efficiency operations (H1), which has a significant and positive impact on operational performance (H2), second, environmental turbulence negatively impact operational and financial performance (H3 and $\mathrm{H} 4$ ), third, operational performance has a significant and positive impact on financial performance (H5). Thus, the study provides better understanding the relationship between resource base and firm performance in the context to rapidly changing business environment.

In-spite of the theoretical contribution the study also offers the important implications for managers. 
For example, first, the concept of competitively distinct operations gained through a series of actions (see measurement scale of CDO) helps managers to make careful alignment between resource choice and operations decisions. Second, the managers are also able to assess the level of turbulent business environment (see measurement scale of TE) this assessment is expected to facilitate the resource choice and operations decisions. Third, the research finding highlights the importance of considering the changing business environment in making resource choice and operations decisions to improve firm performance. This is consistent with the argument made by [53]; according to the authors resources linked with appropriate strategies leads to enhanced performance. Thus, it is plausible to say firm's capabilities to align resource choice and operations decision in the value chain (input-process-output) can be a useful tool not only in mitigating the impact of changing business environment on firm performance but also helps a firm to survive and compete in rapidly changing business environment.

This study was limited to a small sample (61) and does not include adequate sample size to represent entire SMEs in Finland. Considering the values of $\mathrm{R}^{2}$ and PLS path coefficient the research model showed a moderate level of fit, which provides a clear indication for additional research and discussion. The small sample size has been justified for PLS path modelling in the previous research (e.g. $[39,40,56])$. However, as a rule of thumb in PLS path modelling [57] suggests the sample size should be ten times the largest number of formative indicators or ten times the largest number of structural paths directing the construct in the inner path model. Therefore, the future research should consider a larger sample size to examine the relationship between the variables considered in this research (see research model one and two). Also, it would be interesting to see the comparative analysis among the different sector of industries. This will help to generalize the research finding. However, the present study can be taken as a preliminary step that highlights the benefits of aligning resource choice and operations decision in the value chain, hence to enhance the organizational performance in a turbulent business environment.

\section{$\underline{\text { References }}$}

[1] Verdú-Jover A.J., Lloréns-Montes F.J., GarcíaMorales V.J., Environment-flexibility coalignment and performance: an analysis in large versus small firms, Journal of Small Business Management, 44, 3, 334-349, 2006.
[2] Coltman T., Devinney T.M., Modeling the operational capabilities for customized and commoditized services, Journal of Operations Management, 31, 7, 555-566, 2013.

[3] Ketkar S., Sett P.K., Environmental dynamism, human resource flexibility, and firm performance: analysis of a multi-level causal model, The International Journal of Human Resource Management, 21, 8, 1173-1206, 2010.

[4] Schwark B., Influence of regulatory uncertainty on capacity investments - Are investments in new technologies a risk mitigation measure?, 8th Conference on Applied Infrastructure Research (INFRADAY), (No. EPFL-CONF-153004), 2009.

[5] Timilsina B., Competitively distinct operations as a key for superior and sustainable business performance: an example from Walmart, Management, 10, 3, 273-292, 2015.

[6] Vincent F.Y., Hu K.J., An integrated approach for resource allocation in manufacturing plants, Applied Mathematics and Computation, 245, 416-426, 2014.

[7] Chen H., Hsu W.C., Internationalization, resource allocation and firm performance, Industrial Marketing Management, 39, 7, 1103-1110, 2010.

[8] Susarla N., Karimi A.I., Integrated campaing planning and resource allocation in batch plants, Computers \& Chemical Engineering, 35, 12, 2990-3001, 2011.

[9] Lewis M., Slack N., Operations strategy, Pearson/Prentice Hall, 2011.

[10] Schonberger R., Knod M.E., Operations management: continuous improvement, Irwin, Homewood (III), 1994.

[11] Zott C., Dynamic capabilities and the emergence of intraindustry differential firm performance: insights from a simulation study, Strategic Management Journal, 24, 2, 97-125, 2003.

[12] Chase R.B., Jacobs F.R., Aquilano N.J., Operations management for competitive advantage, Boston, ma: McGraw-Hill/Irwin, 2006.

[13] Goodale J.C., Kuratko D.F., Hornsby J.S., Covin J.G., Operations management and corporate entrepreneurship: the moderating effect of operations control on the antecedents of corporate entrepreneurial activity in relation to innovation performance, Journal of Operations Management, 29, 1, 116-27, 2011.

[14] Teece D.J., Pisano G., Shuen A., Dynamic capabilities and strategic management, Strategic Management Journal, 18, 7, 509-533, 1997. 
[15] Falshaw J.R., Glaister K.W., Tatoglu E., Evidence on formal strategic planning and company performance, Management Decision, 44, 1, 9-30, 2006.

[16] Duncan R.B., Perceived environmental characteristics of operational environments and perceived environmental uncertainty, Administrative Science Quarterly, 17, 2, 313-327, 1972.

[17] Holmström J., Realizing the productivity potential of speed, Finnish Academy of Technology, 1995.

[18] Chakravarthy B., A new strategy framework for coping with turbulence, MIT Sloan Management Review, 38, 2, 69-82, 1997.

[19] Kraatz M.S., Zajac E.J., How organizational resources affect strategic change and performance in turbulent environments: theory and evidence, Organization Science, 12, 5, 632-657, 2001.

[20] Gaskill L.A.R., Van Auken H.E., Manning R.A., A factor analytic study of the perceived causes of small business failure, Journal of Small Business Management, 31, 4, 18-31, 1993.

[21] Milliken F.J., Perceiving and interpreting environmental change: an examination of college administrators' interpretation of changing demographics, Academy of Management Journal, 33, 1, 42-63, 1990.

[22] Drucker P., The practice of management, Harper and Row, New York, 1954.

[23] Chandler A., Strategy and structure: chapters in the history of american industrial enterprise, Cambridge Massachusetts, MIT Press, 1962.

[24] Christensen C.R., Andrews K.R., Bower J.L., Hammermesh R.G., Porter M.E., Business policy: text and cases, Homewood, IL: Richard D. Irwin, 1982.

[25] Scott R., Organizations: rational, natural and open systems, Upper Saddle River, NJ: Pearson, 2003.

[26] Emery F., Trist E., The causal texture of organizational environments, Human Relations, 18, 1, 21-32, 1965.

[27] Ansoff H.I., McDonnel E., Implanting strategic management, Prentice-Hall, New York, NY, 1990.

[28] Tsai K.H., Yang S.Y., The contingent value of firm innovativeness for business performance under environmental turbulence, International Entrepreneurship and Management Journal, 10, 2, 343-366, 2014.

[29] Smith M.F., Sinha I., Lancioni R., Forman H., Role of market turbulence in shaping pricing strategy, Industrial Marketing Management, 28, 6, 637-649, 1999.

[30] Stacey Ralph D., Complexity and creativity in organizations, Berrett-Koehler Publishers, 1996.
[31] Boyne G.A., Meier K.J., Environmental turbulence, organizational stability, and public service performance, Administration and Society, 40, 8, 799-824, 2009.

[32] Schon D.A., Beyond the stable state, London: Temple Smith, 1971.

[33] Baum J.R., Wally S., Strategic decision speed and firm performance, Strategic Management Journal, 24, 11, 1107-1129, 2003.

[34] Rosenbusch N., Rauch A., Bausch A., The mediating role of entrepreneurial orientation in the task environment - performance relationship A metaanalysis, Journal of Management, 39, 3, 633-659, 2013.

[35] Wilden R., Gudergan S.P., The impact of dynamic capabilities on operational marketing and technological capabilities: investigating the role of environmental turbulence, Journal of the Academy of Marketing Science, 43, 2, 181-199, 2015.

[36] Farahani H.A., Rahiminezhad A., Same L., A comparison of Partial Least Squares (PLS) and Ordinary Least Squares $(O L S)$ regressions in predicting of couples mental health based on their communicational patterns, Procedia-Social and Behavioral Sciences, 5, 1459-1463, 2010.

[37] Ainuddin R.A., Beamish P.W., Hulland J.S., Rouse M.J., Resource attributes and firm performance in international joint ventures, Journal of World Business, 42, 1, 47-60, 2007.

[38] Chin W.W., The partial least squares approach to structural equation modeling, Modern Methods for Business Research, 295, 2, 295-336, 1998.

[39] Chin W.W., Newsted P.R., Structural equation modeling analysis with small samples using partial least squares, [in:] Statistical strategies for small sample research, R.H. Hoyle [Ed.], 2, 307-342, 1999.

[40] Wold H.O., Introduction to the second generation of multivariate analysis, [in:] Theoretical empiricism: a general rationale for scientific model-building, H.O. Wold [Ed.], pp. VIII-XL, New York, NY: Paragon House, 1989.

[41] Jaworski B.J., Kohli A.K., Market orientation: Antecedents and consequences, Journal of Marketing: a Quarterly Publication of the American Marketing Association, 57, 3, 53-70, 1993.

[42] Camisón C., Villar-López A., Organizational innovation as an enabler of technological innovation $\mathrm{ca}$ pabilities and firm performance, Journal of Business Research, 67, 1, 2891-2902, 2014.

[43] Nunnally J.C., Psychometric theory, 2nd edition, New York: McGraw-Hill, 1978. 
[44] Fornell C., Larcker D.F., Evaluating structural equation models with unobservable variables and measurement error, Journal of Marketing Research, 18, 1, 39-50, 1981.

[45] Cillo P., De Luca L.M., Troilo G., Market information approaches, product innovativeness, and firm performance: an empirical study in the fashion industry, Research Policy, 39, 9, 1242-1252, 2010.

[46] Matzler K., Bidmon S., Grabner-Kräuter S., Individual determinants of brand affect: the role of the personality traits of extraversion and openness to experience, Journal of Product \& Brand Management, 15, 7, 427-434, 2006.

[47] Colucci M., Presutti M., Small firms' relationships and knowledge acquisition: an empirical investigation, Managing Complexity and Change in SMEs: Frontiers in European Research, 50, 2006.

[48] Hamzah Z.L., Othman M.N., Alwi S.F., Corporate brand: online, [in:] Corporate Branding: Areas, arenas and approaches, T.C. Melewar, S.S. Alwi [Eds.], 2015.

[49] Hair J.F., Black W.C., Babin B.J., Anderson R.E., Multivariate data analysis, Englewood Cliffs, NJ: Prentice Hall, 2006.

[50] Falk R.F., Miller N.B., A premier for soft modeling, The University of Akron, Akron, 1992.

[51] Paliszkiewicz J., Koohang A., Gołuchowski J., Horn Nord J., Management trust, organizational trust, and organizational performance: advancing and measuring a theoretical model, Management and Production Engineering Review, 5, 1, 32-41, 2014.

[52] Helfat C.E., Winter S.G., Untangling dynamic and operational capabilities: strategy for the $(N)$ everchanging world, Strategic Management Journal, 32, 11, 1243 Role of entrepreneurship and market orientation in firm's success 1250, 2011.

[53] Edelman L.F., Brush C.G., Manolova T., Coalignment in the resource - performance relationship: strategy as mediator, Journal of Business Venturing, 20, 3, 359-383, 2005.

[54] Akgün A.E., Keskin H., Byrne J., The moderating role of environmental dynamism between firm emotional capability and performance, Journal of Organizational Change Management, 21, 2, 230-252, 2008.

[55] Gonzalez-Benito O., Gonzalez-Benito J., MunozGallego P.A., Role of entrepreneurship and market orientation in firm's success, European Journal of Marketing, 43, 3/4, 500-522, 2009.

[56] Rodríguez-Pinto J., Rodríguez-Escudero A.I., Gutiérrez-Cillán J., Order, positioning, scope and outcomes of market entry, Industrial Marketing Management, 37, 2, 154-166, 2008.

[57] Barclay D.W., Higgins C., Thompson R., The partial least squares approach to causal modeling: personal computer adoption and use as illustration, Technology Studies, 2, 2, 285-309, 1995. 